\title{
World No Tobacco Day 2021: Joining forces for tobacco control
}

\author{
Anil D'Cruz
}

As an oncologist with over 30 years of experience, it is distressing that most cancers are linked to tobacco use and therefore preventable ${ }^{1}$. These figures have remained largely unchanged over the years. Of the lung cancer cases $80-85 \%$ are attributed to tobacco smoking ${ }^{2}$. Tobacco use accounts annually for $11 \%$ of all new cases and $18 \%$ of all cancer deaths globally ${ }^{3}$. While there have been significant efforts worldwide to decrease tobacco use, a lot more needs to be done. The theme for this year's World No Tobacco Day, 'Commit to Quit', draws attention to the need to help and support those addicted to quit the habit, a largely neglected yet very important measure to decrease use.

Tobacco causes 8 million deaths per year, 3 million of which are from cancer. Secondhand smoke kills over 1 million people per year, including 65000 children. There are 1.3 billion smokers globally, with $80 \%$ living in LMICs. In addition, many in the South-East Asian region use smokeless tobacco, the main cause for the high incidence of head and neck cancers in the region ${ }^{4}$. Tobacco not only affects the health of people, but also costs countries money in terms of healthcare costs and lost productivity. It has been shown that the impact of health expenditure on national economies due to tobacco related illnesses is much higher than the income revenue from the sales of tobacco products. In addition, smoking among cancer survivors remains a problem with one longitudinal study showing almost $10 \%$ of cancer survivors smoking for 9 years after their diagnosis ${ }^{5}$, illustrating the importance of developing comprehensive cessation/support programs for cancer patients who smoke.

\section{World No Tobacco Day: 'Commit to Quit'}

Today is World No Tobacco Day, an occasion to remind the public and the international health community that tobacco remains among the most important risk factors for cancer and non-communicable diseases (NCDs).

This year, WHO has launched a full year campaign ${ }^{6}$ focusing on smoking cessation. Cessation programs are cost effective and have long-term health benefits. The campaign aims to reduce the number of tobacco users globally by empowering them to quit, using multiple tools such as 'Florence', WHO's digital health worker, powered by artificial intelligence ${ }^{7}$. Cessation programs include psychological support ${ }^{8}$, and approved nicotine replacement therapies $(\mathrm{NRT})^{9}$ that can help smokers to succeed in their efforts to quit. New products are heavily marketed ${ }^{10}$ as alternatives to smoking such as tobacco pouches, e-cigarettes and HTPs. However, we still do not know whether these products are effective in helping adults quit conventional cigarettes nor their long-term health consequences ${ }^{11}$.

From a public health perspective, multiple measures can be taken to help people quit tobacco. For instance, tobacco taxation and increases in prices have been shown to decrease smoking prevalence, making cigarettes less affordable ${ }^{12}$. Furthermore, developing smoke-free places increases the
AFFILIATION

1 Union for International Cancer

Control, Geneva, Switzerland

CORRESPONDENCE TO

Anil D'Cruz. Union for International Cancer Control, Geneva,

Switzerland. E-mail: advocacy@ uicc.org

KEYWORDS

cancer control, WNTD, cancer, FCTC

Received: 27 May 2021

Accepted: 28 May 2021 
chances of successfully quitting smoking, reducing secondhand smoke exposure and has the added benefit of preventing the 'normalization' of tobacco use in public, which is particularly important for teenagers and children ${ }^{13}$. It is important that there is strong legislation with the enforcement of laws that ban tobacco advertising, promotion and sponsorship, as studies have shown that direct or indirect marketing approaches increase the likelihood of people continuing to use tobacco and promote public perceptions of smoking as socially acceptable ${ }^{14}$.

\section{A multi-stakeholders' approach}

As a global cancer control organization, tobacco control is a priority area for the Union for International Cancer Control (UICG). To make real and sustained progress in reducing tobacco use, we must work across the health sector and with other sectors that are critical to tobacco control efforts including the labor, business and environment sectors. The social cost of tobacco is severe and affects several areas. We know that people deprive themselves of food in order to buy tobacco and that tobacco use is linked to poverty with people on low incomes more likely to smoke. Tobacco has a detrimental impact on the environment due to intensive farming and its impact on the water supply and because cultivating tobacco contributes to deforestation and land degradation.

We have the tools to accelerate progress in tobacco control. It is very encouraging that countries are increasingly implementing measures supporting the WHO Framework Convention for Tobacco Control (FTCT) where, in 2019 , about $65 \%$ of the world's population was covered by at least one MPOWER measure, up from only $15 \%$ in $2007^{15}$. We have witnessed a decrease in smoking prevalence globally over the last decade ${ }^{15,16}$ and millions of lives have been saved from tobacco related illness and death. However, we still have much work to do to further reduce the tobacco epidemic by investing in tobacco control measures and fighting the influence of the industry. By joining forces with the tobacco control community, the cancer and NCD community, along with organizations from other sectors, can lobby governments to put strong tobacco control measures in place. We saw the result of these combined efforts recently where after strong lobbying from NGOs, Philip Morris was removed from sponsoring and participating in a major conference in Asia. We owe it to future generations to take action now to protect their health. Tobacco control must be at the heart of these efforts.

\section{REFERENCES}

1. World Cancer Report: Cancer Research for Cancer Prevention. International Agency for Research on Cancer, World Health Organization; 2020. World Cancer Reports.

2. What Are the Risk Factors for Lung Cancer? Centers for Disease Control and Prevention. Updated September 22, 2020. Accessed May 25, 2021. https://www.cdc.gov/ cancer/lung/basic_info/risk_factors.htm

3. Sung H, Ferlay J, Siegel RL, et al. Global Cancer Statistics 2020: GLOBOCAN Estimates of Incidence and Mortality Worldwide for 36 Cancers in 185 Countries. CA Cancer J Clin. 2021;71(3):209-249. doi:10.3322/caac.21660

4. Siddiqi K, Husain S, Vidyasagaran A, Readshaw A, Mishu MP, Sheikh A. Global burden of disease due to smokeless tobacco consumption in adults: an updated analysis of data from 127 countries. BMC Med. 2020;18:222. doi:10.1186/s12916-020-01677-9

5. Westmaas JL, Alcaraz KI, Berg CB, Stein KD. Prevalence and Correlates of Smoking and Cessation-Related Behavior among Survivors of Ten Cancers: Findings from a Nationwide Survey Nine Years after Diagnosis. Cancer Epidemiol Biomarkers Prev. 2014;23(9):1783-1792. doi:10.1158/1055-9965.EPI-14-0046

6. World Health Organization. WHO launches year-long campaign to help 100 million people quit tobacco. World Health Organization. December 8, 2020. Accessed May 25, 2021. https://www.who.int/news/item/08-12-2020who-launches-year-long-campaign-to-help-100-millionpeople-quit-tobacco

7. World Health Organization. Using AI to quit tobacco: Quit tobacco today! World Health Organization. Accessed May 25, 2021. https://www.who.int/news-room/spotlight/ using-ai-to-quit-tobacco

8. American Cancer Society. Ways to Quit Tobacco Without Using Medicines. Cander.org. Updated October 10, 2020. Accessed May 25, 2021. https://www.cancer.org/healthy/ stay-away-from-tobacco/guide-quitting-smoking/otherways-to-quit-smoking.html

9. American Cancer Society. Nicotine Replacement Therapy to Help You Quit Tobacco. Cancer.org. Updated October 10, 2020. Accessed May 25, 2021. https://www.cancer. org/healthy/stay-away-from-tobacco/guide-quittingsmoking/nicotine-replacement-therapy.html

10. University of Bath. E-cigarettes: Marketing. TobaccoTactics. Updated February 5, 2020. Accessed May 25, 2021. https://tobaccotactics.org/wiki/e-cigarettesmarketing/

11. American Cancer Society. Health Risks of E-cigarettes. Cancer.org. Updated October 28, 2020. Accessed May 
25, 2021. https://www.cancer.org/healthy/stay-awayfrom-tobacco/health-risks-of-tobacco/health-risks-of-ecigarettes.html

12. Bader P, Boisclair, Ferrence R. Effects of Tobacco Taxation and Pricing on Smoking Behavior in High Risk Populations: A Knowledge Synthesis. Int J Environ Res Public Health. 2011;8(11):4118-4139. doi:10.3390/ijerph8114118

13. Smoking and Tobacco Use: Smokefree Policies Reduce Smoking. Centres for Disease Control and Prevention. Accessed May 25, 2021. https://www.cdc.gov/tobacco/ data_statistics/fact_sheets/secondhand_smoke/ protection/reduce_smoking/index.htm

14. World Health Organization. Tobacco Control in Practice Case studies of implementation of the WHO Framework Convention on Tobacco Control in the WHO European Region: Article 13: Tobacco advertising, promotion and sponsorship. Regional Office for Europe, World Health Organization; 2012. Accessed May 15, 2021. https:// www.euro.who.int/_data/assets/pdf_file/0009/166905/ E96595.pdf

15. World Health Organization. WHO report on the global tobacco epidemic, 2019: offer to help to quit tobacco use. World Health Organization, 2019. Accessed May 25, 2021. https://www.who.int/teams/health-promotion/ tobacco-control/who-report-on-the-global-tobaccoepidemic-2019

16. Jihnson S, Tittenbrun Z, Romero Y, et al. The World Cancer Declaration: time to consolidate wins and work towards 2025. The Lancet Oncol. 2021;22(3):296-298. doi:10.1016/S1470-2045(21)00012-7
CONFLICTS OF INTEREST

The author has completed and submitted the ICMJE Form for Disclosure of Potential Conflicts of Interest. The author reports honorary grants from Merck India and Biocon Biologics, outside the submitted work. The author also reports being an honorary advisory member of $\mathrm{V}$ Care Foundation Board of Trustees, and a board member of Prince Ali Khan Hospital Mumbai.

FUNDING

There was no source of funding for this research.

ETHICAL APPROVAL AND INFORMED CONSENT

Ethical approval and informed consent were not required for this study.

PROVENANCE AND PEER REVIEW

Commissioned; internally peer reviewed. 